\title{
PENYUSUNAN FEATURE MODEL DENGAN PENDEKATAN FODA. STUDI KASUS APLIKASI ELEARNING UNIVERSITAS MERCUBUANA
}

\author{
Satrio Yudho, Tri Daryanto \\ Program Studi Teknik Informatika, Fakultas Teknologi Informasi, Universitas Budi Luhur \\ E-mail : yudhos@gmail.com, trid umb@mercubuana.ac.id
}

\begin{abstract}
One of the roles in information and communication technology to improve the quality of learning and teaching in educational organizations is to conduct a web-based learning facility that e-learning. In general, there are two types of software that is generic and bespoke (customized), in this study we found that the university mercubuana customized using generic applications. Featured model is a way to define the functionality of the application based on the features required by user features, the features of these features can be grouped based on necessity (mandatory) and supplementary (optional). Preparation of requirements-based features proposed in this study is intended as the reference management application requirements e-learning mapped clearly and well. So it can be helpful to the development of future applications.
\end{abstract}

Keywords: E-Learning, feature models, mandatory and optional

\section{PENDAHULUAN}

Perkembangan kemajuan teknologi komunikasi data berbasis internet mendorong perguruan tinggi ke arah inisiatif pemanfaatan aplikasi berbasis internet untuk mendukung kegiatan belajar mengajar yang umum disebut ELearning.

Menurut Darin E. Hartley yang dikutip dari wahono(1), "eLearning merupakan suatu jenis belajar mengajar yang memungkinkan tersampaikannya bahan ajar ke siswa dengan menggunakan media Internet, Intranet atau media jaringan komputer lain.", menurut LearnFrame.Com dalam Glossary of eLearning Terms dikutip dari wahono (1) menyatakan suatu definisi yang lebih luas bahwa: "eLearning adalah sistem pendidikan yang menggunakan aplikasi elektronik untuk mendukung belajar mengajar dengan media Internet, jaringan komputer,maupun komputer standalone."

Dari dua definisi diatas terlihat bahwa dalam pengertian elearning terdapat dua aspek yakni sistem pembelajaran dan teknlogi berupa aplikasi.Dalam penelitian ini kami menitikberatkan pada aplikasi elearning. Aplikasi secara definisi termasuk kedalam perangkat lunak, seperti yang dikutip dari open project (2) "Software is a generic term for organized collections of computer data and instructions" , dan dalam konteks ini aplikasi elearning termasuk kedalam webbased software (3)

Setiap perangkat lunak haruslah memiliki dokumentasi (3)yang baik terkait dengan fungsinya sebagai pendukung aktifitas, dokumentasi ini berperan sebagai acuan dan sejarah aplikasi tersebut semenjak tahapan inisiasi hingga implementasi.

Pengelolaan requirements perangkat lunak selalu menjadi tantangan dalam setiap organisasi dan akan lebih meningkat lagi apabila terdapat penggunaan perangkat lunak dengan jenis generic, menurut sommerville (4), perangkat lunak yang baik memiliki ciri ciri Maintainability, Dependability,
Efficiency, Usablity. Untuk memenuhi keempat ciri tersebut, perangkat lunak harus diawali dengan langkah langkah pengembangan yang tepat, atau minimal jika menggunakan generic opensource software harus memiliki dokumntasi yang direpresentasikan dalam bentuk symbol dalam metode pengembangan tertentu, dalam penelitian ini kami akan melakukan eskplorasi kebutuhan pengguna aplikasi dengan melihat kepada jenis perangkat lunak generic yang digunakan serta mengelompokan fitur fitur yang ada untuk mendefinisikan requirements.

Setiap requirements tersebut akan merefleksikan kebutuhan dasar dari pengguna atau stakeholder, seperti yang dijelaskan pada piramida requirements (5) berikut:

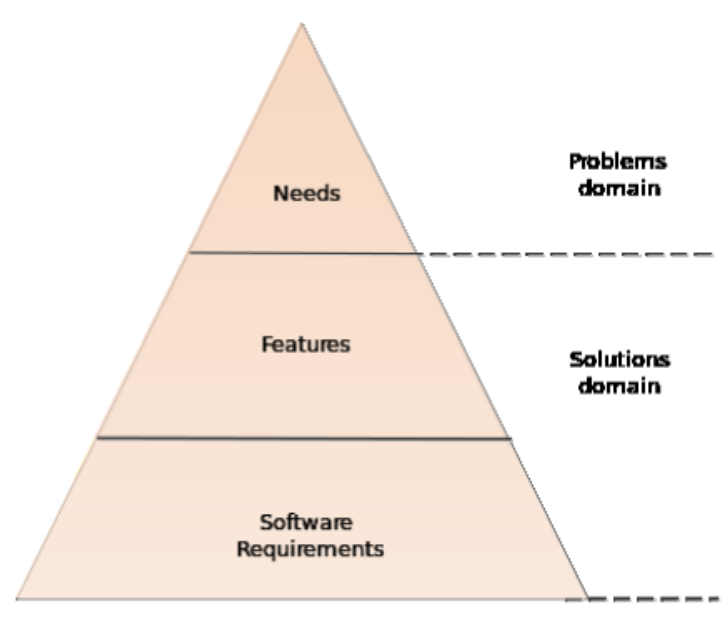

Gambar I.1 Piramida Requirements(5)

Pratap Mohapatra (6)mendefinisikan fitur sebagai berikut " $A$ feature is a service that the system provides to fulfill one or more stakeholder needs", Needs dalam aplikasi elearning ini adalah kebutuhan yang mutlak harus bersumber dari stakeholder. 
Kang et al (7) mendefinisikan feature model sebagai berikut $: A$ feature model describes features-the common or variable characteristics of the products in a SPL-as a visual hierarchy with additional constraints between features.

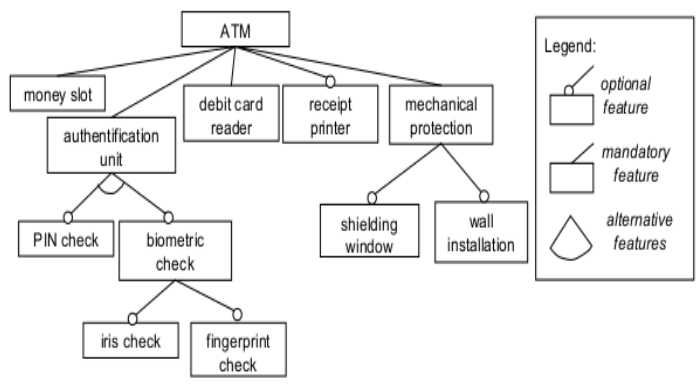

Gambar I.1 Feature Model (8)

Metode yang digunakan oleh Kang adalah Feature Oriented Domain Analysis (FODA), tujuan utama dari FODA adalah untuk memetakan fitur berdasarkan keharusan (mandatory) dan pelengkap (optional) dalam aplikasi sejenis yang digunakan untuk pengembangan jangka panjang pada pengguna yang berbeda. Bisa dikatakan bahwa aplikasi elearning adalah sebuah aplikasi yang bisa digunakan oleh banyak pengguna dengan beberapa jenis kepentingan yang sama maupun spesifik.

\section{I.1. PERUMUSAN MASALAH} adalah :

Perumusan masalah pada penelitian ini

1. Seperti apakah feature model dari aplikasi elearning universitas mercubuana yang ada saat ini?

2. Bagaimanakah model fitur aplikasi elearning mendatang berdasarkan metode FODA ?

\section{TUJUAN PENELITIAN}

Tujuan penelitian ini adalah untuk membuat susunan Software requirements berupa fitur fitur aplikasi elearning yang berguna untuk panduan pengembangan aplikasi dimasa mendatang.

Susunan tersebut menggambarkan kelompok kelompok kebutuhan pengguna dalam aplikasi, kebutuhan kebutuhan (requirements) tersebut terbagi atas dua jenis yakni :

1. Mandatory requirements

2. Optional Requirements

Dengan terbentuknya model tersebut, akan terlihat keterkaitan antara fitur fitur dalam aplikasi elearning.

\section{METODOLOGI}

Desain penelitian ini kami menyusun tiga tahapan utama yakni:

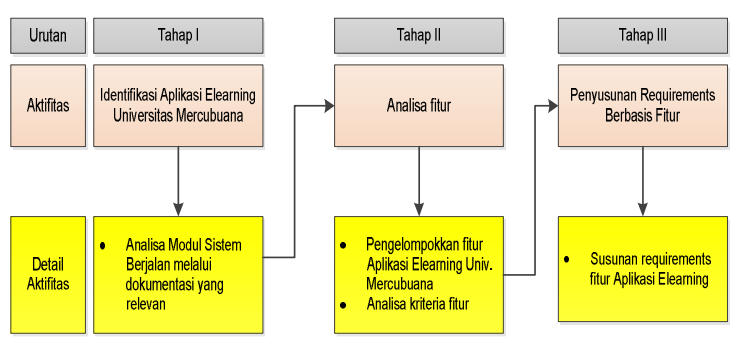

Gambar III.3 Metodologi

Tahap I, identifikasi, tahapan identifikasi adalah kegiatan pengamatan aplikasi elearning yang saat ini digunakan, tujuannya adalah memetakan fitur fitur yang sudah disediakan oleh pengembang aplikasi dalam bentuk feature model.

Tahap II Analisa Fitur, tujuan dari requirements recovery adalah untuk melihat kebutuhan stakeholder akan elearning system, yang kemudian akan di analisa dengan fitur yang sudah tersedia pada tahap I yang kemudian dianalisa untuk melihat fitur mana saja yang mandatory dan optional.

Tahap III Penyusunan Feature Model, penyusunan feature model yang sudah diselaraskan antara aplikasi saat ini dengan kebutuhan pengguna.

\section{III.1. Tinjauan Pustaka}

Menurut Pratap Mohapatra (6)fitur didefinisikan sebagai berikut "A feature is a service that the system provides to fulfill one or more stakeholder needs"

Dari teori tersebut dapat dipahami bahwa needs dan feature merupakan gambaran dari apa saja yang user inginkan, secara fungsional, kebutuhan mungkin dapat ditangkap dengan baik oleh pengguna, namun apakah fitur fitur pendukung juga dapat teridentifikasi ?, seperti, keamanan website, respon time, jumlah akses, besarnya data yang dapat di upload, pilihan perfomaance aplikasi di user dan lain sebagainya.

Tidak semua pengguna dapat mengungkapkan apa yang menjadi kebutuhan mereka secara lengkap, hal ini di perparah lagi dengan banyaknya application template yang menawarkan aplikasi "siap jadi" yang sarat dengan fitur, namun apakah keseluruhan fitur tersebut sudah sesuai dengan kebutuhan ? bagaimana dengan kompabilitas perangkat keras dan jaringan komputer.

Analisa fitur ini menggunakan metode yang diusulkan oleh Kang (7) "The primary focus of the method is the identification of prominent ordistinctive features of software systems in a domain. These features areuser-visible aspects or characteristics of the domain. They lead to thecreation of a set of products that define the domain and also give themethod its name: FeatureOriented Domain Analysis (FODA). The featuresdefine both common aspects of the domain as well as differencesbetween related systems in the domain." 
Hasil analisa fitur requirements dari Kang, adalah kelompok kelompok fitur yang nyata di butuhkan oleh pengguna aplikasi, kemudian dari analisa kang tersebut fitur fitur yang ada akan di modelkan berdasarkan tingkat kepentingan pada kebutuhan saat ini namun juga tidak mengabaikan fitur mendatang seperti yang dikutip dari riebisch (8) adalah sebagai berikut :

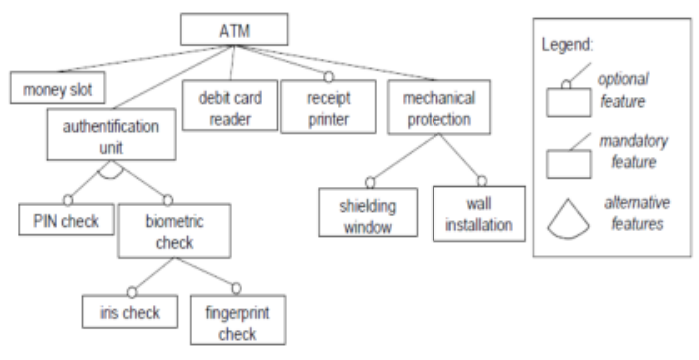

Gambar III.4 Model Fitur(8)

Terdapat tiga jenis fitur yakni, optional feature, mandatory feature dan alternative feature. Ketiga jenis fitur ini didefinisikan berdasarkan kebutuhan pengguna, dalam analisis FODA, pengguna akan di kelompokkan kedalam Domain Expert. Tidak semua pengguna dapat menentukan fitur, perlu dilakukan klarifikasi mengenai siapa saja yang termasuk kedalam domain expert tersebut.

Sebagai contoh, dari setiap domain expertterdapat grup grup unit pengguna, dalam hal ini adalah fakultas yang ada di dalam universitas mercubuana, setiap fakultas memiliki persamaan dan perbedaan kebutuhan, seperti gambar berikut:

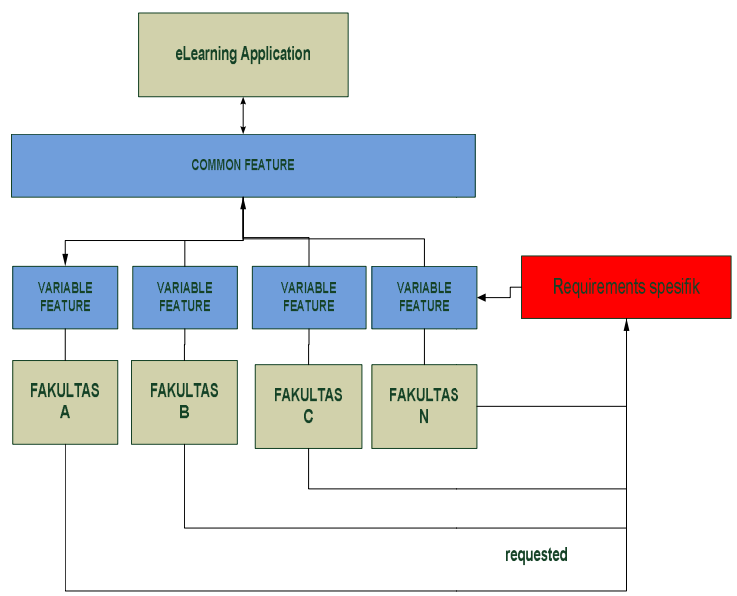

Gambar III.2 Struktur Fitur

Kebutuhan di setiap fakultas akan sangat mempengaruhi munculnya fitur serta harapan user dan kepuasan user dalam menggunakan aplikasi tersebut. Harapan dan kebutuhan user dapat dimunculkan dengan menggali aplikasi yang saat ini digunakan, metoda yang digunakan untuk mendapatkan informasi terkait hal tersebut adalah dengan melakukan reverse engineering dari model fitur aplikasi saat ini. Menurut somerville (4) prosedur yang dilakukan untuk melakukan reverse engineering dari model fitur adalah dengan melakukan identifikasi dan merekonstruksi group feature dan mandatory feature beradarsakan artefak aplikasi berupa screenshot, executeables, dan set documentation terkait aplikasi tersebut.

\section{HASIL DAN PEMBAHASAN}

Berdasarkan hasil penelusuran kami di area riset, berikut ini adalah needs yang disediakan oleh aplikasi elearning universitas mercubuana(9):

Tabel IV.1. Artefak Fitur Aplikasi Elearning

\begin{tabular}{|c|l|}
\hline Needs & \multicolumn{1}{|c|}{ Deskripsi } \\
\hline 1. & Mengkases materi kuliah \\
\hline 2. & Mengerjakan Tugas \\
\hline 3. & diskusi \\
\hline 4. & Membaca penugasan (Assignment) \\
\hline 5. & Presentasi materi \\
\hline 6. & Dialog antara dosen dengan mahasiswa \\
\hline 7. & $\begin{array}{l}\text { Dialog antara mahasiswa dengan sumber } \\
\text { belajar }\end{array}$ \\
\hline 8. & $\begin{array}{l}\text { Dialog di antara mahasiswa melalui } \\
\text { elearning UMB }\end{array}$ \\
\hline 9. & Akses bahan kuliah \\
\hline 10. & menjawab pertanyaan dalam diskusi \\
\hline 11 & Mengerjakan tugas \\
\hline 12 & Evaluasi mahasiswa \\
\hline
\end{tabular}

Menurut piramida requirements yang dikemukakan oleh leffingwell (5), pemodelan kebutuhan merupakan representasi dari problem domain yang dibutuhkan oleh pengguna.

Berdasarkan dari buku panduan pengguna elearning (9) yang diterbikan oleh universitas mercubuana, kami berasumsi bahwa fitur fitur aplikasi elearning tersebut adalah fitur yang dibutuhkan oleh pengguna yakni dosen dan mahasiswa.

Setiap pengguna yang berada dalam lingkungan akademik universitas mercubuana terbagi atas kelompok kelompok pengguna yang disebut dengan fakultas dan program studi, dalam penelitian ini kami akan melakukan analisa apakah terdapat perbedaan atau perusamaan kebutuhan pada setiap pengguna aplikasi. Hasil pengelompokkan fitur ini akan dibandingkan dengan beberapa fitur aplikasi elearning lain dalam bagian analisa.

\section{IV.1. Analisis}

Untuk dapat menentukan fitur mana saja yang termasuk mandatory atau optional, kami menggunakan perbandingan dengan aplikasi elearning yang dikembangkan oleh moodle(10)dengan aplikasi elearning moodle universitas mercubuana yang saat ini tengah digunakan.

Menurut Jason Cole (11)Secara umum sebuah Learning management system(LMS) harus memiliki fungsi fungsi sebagai berikut : 
Tabel IV.2 Fungsi Yang Harus Ada Pada LMS (11)

\begin{tabular}{|c|l|}
\hline No. & \multicolumn{1}{|c|}{ Fitur } \\
\hline 1. & Uploading and Sharing Materials \\
\hline 2. & Forums and Chats \\
\hline 3. & Quiz and Surveys \\
\hline 4. & Gathering and receiving Assignments \\
\hline 5. & Recording Grades \\
\hline
\end{tabular}

Secara fungsional, fitur fitur tersebut berhubungan dengan kebutuhan pengguna dalam menyelenggarakan aktifitas belajar dan mengajar melalui media LMS, pengguna yang dimaksud adalah fakultas fakultas yang ada dalam lingkungan akademik universitas mercubuana, pengguna tersebut di kelompokkan sebagai berikut :

Tabel IV.3 Daftar Fakultas UMB (9)

\begin{tabular}{|c|l|}
\hline No. & \multicolumn{1}{|c|}{ Fakultas } \\
\hline 1. & Fakultas Ilmu Komputer \\
\hline 2. & Fakultas Ekonomi dan Bisnis \\
\hline 3. & Fakultas ilmu komunikasi \\
\hline 4. & Fakultas Psikologi \\
\hline 5. & Fakultas Teknologi industri \\
\hline 6. & Fakultas Teknik sipil dan perencanaan \\
\hline
\end{tabular}

Perbandingan antara fitur (functional requirements) yang secara global disediakan moodle dengan kebutuhan fitur yang diperlukan pengguna (9) adalah sebagai berikut:

Tabel IV.4 Matriks Fitur Jason Cole(11), Moodle(10) Dan Pengguna(9)

\begin{tabular}{|c|c|c|c|c|c|c|}
\hline \multirow{2}{*}{ Fitur } & \multicolumn{6}{|c|}{ Fakultas } \\
\hline & $=0$ & $=0$ & $E$ & क. & - & ర జ \\
\hline Uploading and sharing materials (11) & M & M & M & M & M & M \\
\hline Mengelola ringkasan dan label & M & M & M & M & M & M \\
\hline Menambahkan ringkasan & M & M & M & M & M & M \\
\hline Menambahkan label & M & M & M & M & M & M \\
\hline Mengelola bahan ajar & M & M & M & M & M & M \\
\hline $\begin{array}{l}\text { Mengelola bahan ajar } \\
\text { berbentuk teks }\end{array}$ & 0 & 0 & 0 & 0 & 0 & $\mathrm{O}$ \\
\hline $\begin{array}{l}\text { Mengelola bahan ajar } \\
\text { berbentuk web }\end{array}$ & $\mathrm{O}$ & 0 & O & $\mathrm{O}$ & $\mathrm{O}$ & 0 \\
\hline
\end{tabular}

\begin{tabular}{|c|c|c|c|c|c|c|}
\hline \multirow{2}{*}{ Fitur } & \multicolumn{6}{|c|}{ Fakultas } \\
\hline & $\circ$ & ᄃ o & $\varepsilon$ & s.- & - & ठ \\
\hline $\begin{array}{l}\text { Mengelola bahan ajar } \\
\text { berbentuk file }\end{array}$ & O & 0 & $\mathrm{O}$ & $\mathrm{O}$ & 0 & O \\
\hline Forums and Chats (11) & M & $\mathrm{M}$ & $M$ & $M$ & $M$ & M \\
\hline Membuat forum diskusi & M & $\mathrm{M}$ & $M$ & $M$ & $M$ & $M$ \\
\hline Membalas pesan & M & M & M & $M$ & M & M \\
\hline Mengomentari topic diskusi & M & $\mathrm{M}$ & M & M & M & M \\
\hline Menilai posting & $M$ & $M$ & $M$ & $M$ & $M$ & $M$ \\
\hline Quiz and Surveys (11) & M & M & M & $M$ & $M$ & M \\
\hline Menambahkan kuis & M & M & M & M & M & M \\
\hline Pengelolaan bank soal & $M$ & $M$ & $M$ & $M$ & $M$ & M \\
\hline Membuat kategori soal & $M$ & $\mathrm{M}$ & $M$ & $M$ & $M$ & M \\
\hline Membuat soal multiple choice & M & $\mathrm{M}$ & M & M & M & M \\
\hline Membuat soal True False & M & M & M & M & M & M \\
\hline Membuat Soal Essay & M & M & M & $\mathrm{M}$ & $\mathrm{M}$ & M \\
\hline $\begin{array}{l}\text { Gathering and receiving Assignments } \\
\text { (11) }\end{array}$ & M & M & M & M & M & M \\
\hline Memberikan tugas upload single file & M & M & M & M & M & M \\
\hline Pemberian tugas kegiatan offline & M & $\mathrm{M}$ & M & M & M & M \\
\hline Pemberian komentar dan nilai tugas & M & M & M & M & M & M \\
\hline Recording Grades (11) & M & M & M & M & M & M \\
\hline Merekap aktifitas forum mahasiswa & M & M & M & M & M & M \\
\hline Merekap nilai jawaban kuis & M & M & M & M & M & M \\
\hline Fitur Lain & - & - & - & - & - & - \\
\hline Register & M & M & M & $M$ & M & M \\
\hline Login & $M$ & $M$ & $M$ & $M$ & $M$ & $M$ \\
\hline Mengubah profil & O & O & O & 0 & 0 & $\mathrm{O}$ \\
\hline Display halaman elearning Fakultas & 0 & 0 & 0 & 0 & 0 & 0 \\
\hline Ubah bahasa & $\mathrm{O}$ & 0 & O & 0 & 0 & $\mathrm{O}$ \\
\hline $\begin{array}{l}\text { Display Ekternal link pada tampilan layar } \\
\text { awal situs }\end{array}$ & $\mathrm{O}$ & 0 & 0 & 0 & 0 & $\mathrm{O}$ \\
\hline Social media plugins & $\mathrm{O}$ & 0 & 0 & 0 & 0 & $\mathrm{O}$ \\
\hline Display calendar & $\mathrm{O}$ & 0 & 0 & 0 & 0 & $\mathrm{O}$ \\
\hline Display kategori mata kuliah & 0 & $\mathrm{O}$ & 0 & 0 & 0 & 0 \\
\hline
\end{tabular}

Kami melakukan identifikasi dua kelompok fitur dengan memberikan symbol (M) untuk mandatory dan (O) untuk optional, Penentuan kelompok fitur didasarkan pada kebutuhan pengguna yang didefinisikan pada buku pengguna elearning(9)

Dari matriks diatas, kami mencoba untuk mentransformasikan susunan fitur tersebut ke dalam bentuk Diagram fitur yang diadopsi dari Kang (7) dan Riesbich (8), sebagai berikut:

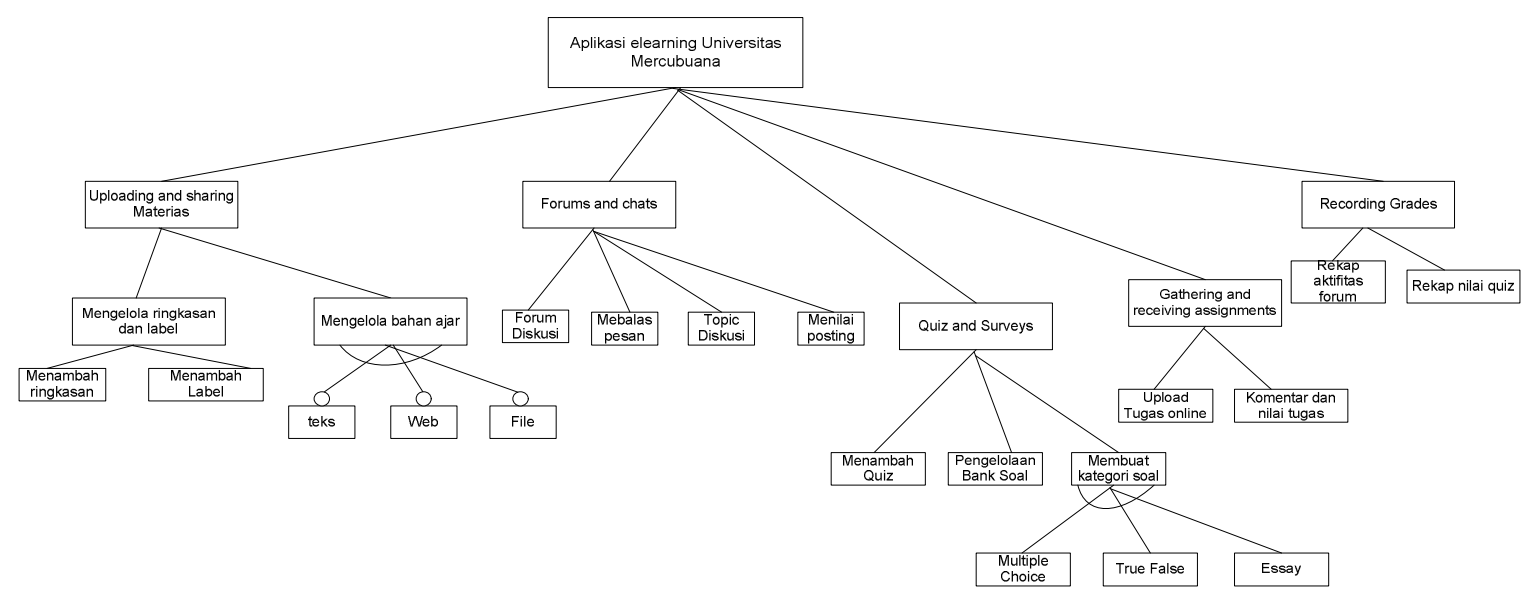

Gambar IV.6 Feature Model Aplikasi Elearning 


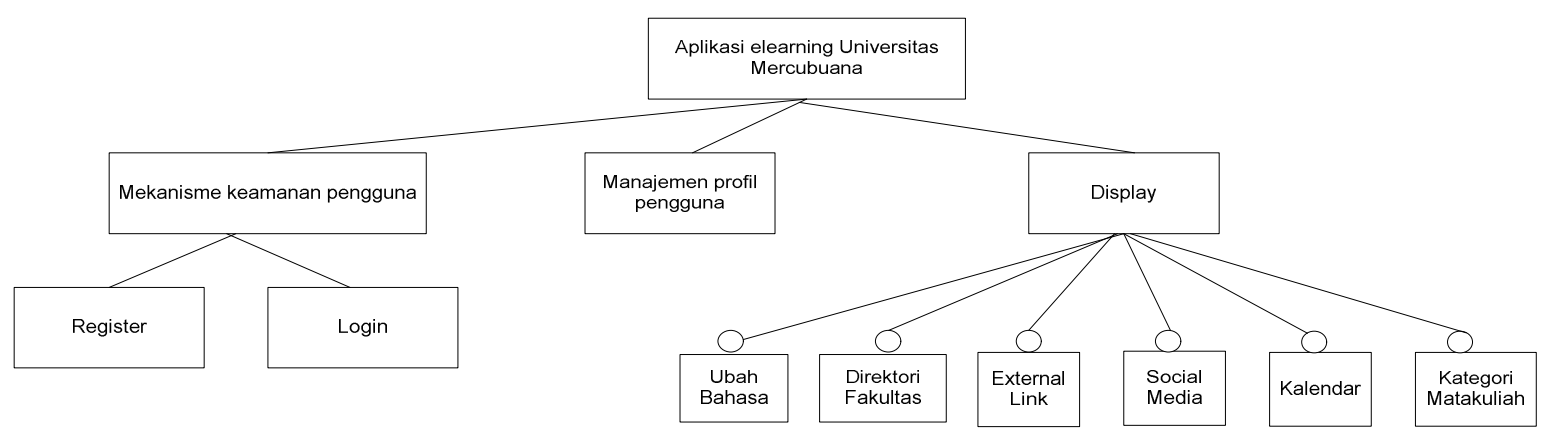

Gambar IV.7 Feature Model Aplikasi Elearning (Lanjutan)

\section{KESIMPULAN DAN SARAN}

\section{V.1. Kesimpulan}

Dari hasil penelitian kami, kesimpulan yang dihasilkan adalah bahwa penyusunan requirements berbentuk feature model akan lebih memudahkan pengembangan aplikasi dengan cara melihat struktur fungsionalitas aplikasi, feature model berperan sebagai peta dari fungsi fungsi yang ada, dimana setiap fungsi tersebut dikelompokkan pada nilai mandatory atau optional.

Nilai mandatory atau optional inilah yang akan mempengaruhi interaksi aplikasi pada setiap pengguna. Oleh sebab itu feature model dapat menjadi salah satu acuan untuk memahami perbedaan kebutuhan pengguna pada satu jenis aplikasi.

\section{V.2. Saran}

Penggunaan feature model sebagai panduan pengembangan aplikasi dimasa mendatang perlu dilakukan kajian yang lebih kuantitatif pada aspek keamanan dan kestabilan dari setiap requirements di dalam fitur. Kajian kuantitatif ini akan mengarah kepada pemenuhan kebutuhan pembelajaran yang berbeda pada setiap fakultas atau program studi, yang tentunya sangat relevan dengan visi dan misi pendidikan di dalamnya.

Untuk penelitian selanjutnya terkait dengan hasil penelitian ini adalah bagaimana pengukuran atau scoring model dari setiap fitur di setiap pengguna?

\section{REFERENSI}

[1]. Cole, Jason.Using Moodle. s.I. : O'reilly, 2005.

[2]. K. Kang, S. Cohen, J. Hess, W.Nowak, S.Peterson.Feature Oriented Domain Analysis (FODA). s.I. : Technical Report CMU/SEI-90TR21, 1990.

[3]. Mohapatra, Pratap K.J.Software Engineering (A life cycle Approach). s.l.: New Age International Publishers, 2010.

[4]. Moodle. [Online] [Cited: Juni 24, 2014.] http://docs.moodle.org/27/en/Features.

[5]. projects, Open. [Online] [Cited: Juni 06, 2014.] http://www.openprojects.org/softwaredefinition.htm.

[6]. Pressman, Roger S.Software Engineering, Practitioner's Guide. s.I. : McGraw Hill, 2001

[7]. Sommerville, lan.Software Engineering 8th edition. s.I. : China Machine Press, 2001.

[8]. Suharno Pawirosumanto, Ida Farida.Panduan Penggunaan dan Pengembangan Pembelajaran dengan LMS Moodle. s.I. : Mitra Wacana Media, 2011.

[9]. Towards a More Precise Defintion of Feature Models. Riesbich, Matthias. 2003, Universitas Hamburg

[10]. Wahono, Romi Satria. [Online] [Cited: Juni 2014, 2014.]

http://romisatriawahono.net/2008/01/23meluru skan-salah-kaprah-tentang-elearning/.

[11]. Widrig, D Leffingwell D.Managing Software Requirements - A Unified Approach. s.l. : Addison-Wesley Longman, 2000. 